\title{
Use of Apps in Pharmacy as a Communication tool
}

\author{
M. Hosseini (Mohammad Hosseini), M. Luliak (Milan Luliak)
}

University of Health and Social Work St. Elizabeth, Bratislava, Slovakia.

\section{E-mail address:}

mh26041980@gmail.com

\section{Reprint address:}

Milan Luliak

University of Health and Social Work St. Elizabeth

Bratislava

Slovakia

Source: Clinical Social Work and Health Intervention

Pages: $49-52$

Volume: 12

Issue: 2

\section{Reviewers:}

Andrea Shahum,

University of North Carolina at Chapel Hill School of Medicine, USA

Steve Szydlowski

University of Scranton school of education, USA

\section{Keywords:}

Digitalization. Communication Tool. Patients. Medicines. Health.

\section{Publisher:}

International Society of Applied Preventive Medicine i-gap

CSWHI 2021; 12(2): 49 - 52; DOI: 10.22359/cswhi_12_2_09 (C) Clinical Social Work and Health Intervention

\section{Abstract:}

In Germany, around 58 million people currently use a smartphone. ${ }^{1}$ Not to use this communicative access to potential customers on the part of the health market would not only be negligent, but also unrealistic. Digitalization in the health sector has developed strongly in many areas in recent years and is described with different terms. These include 'e-health', 'digital health' or 'health 2.0 '. However, all these terms mean the same thing: techniques and digital applications for preventing, improving and maintaining the health of the population. The tools of this technology are websites, portals, forums and, above all, apps. They are all intended to support people in actively shaping their health. ${ }^{2}$

\footnotetext{
${ }^{1}$ Source: Statista, statistics on smartphone usage in Germany, published on 8.2.21.

${ }^{2}$ Knoppler \& Stendera, 2019, p. 83.
} 


\section{Digital applications in the health sector}

In the category 'Health and Fitness' there are currently over 100,000 different apps available. In the category 'Medicine' there are another 46,000 apps $^{3}$ The offer is diverse and partly confusing. In a Bertelsmann study from 2016, Knöppler et al. derived a systematization of digital health applications and divided them into seven application types. This subdivision facilitates the overview and is structured as follows: ${ }^{4}$

Group 1: Basic application with a medical purpose such as prevention or therapy:

- Type 1 'Strengthening health literacy': The user is provided with general health-related knowledge in order to be able to act in a self-determined healthy way.

- Type 2 'Analysis and insight': The user receives health information with a specific personal context.

- Type 3 'Indirect intervention': Promoting selfefficacy, adherence \& safety': monitoring of the patient with continuous personal context.

- Type 4 'Direct Intervention': Changing skills, behaviors \& states': Therapy apps are used in addition to therapy to bring about long-term change.

Group 2: Complementary applications with administrative or service reference

- Type 5 'Documentation of health and medical history': Creation of a digital health record.

- Type 6 'Organization and administration': Digital contact with doctors' practices, hospitals or health insurance companies.

- Type 7 'Purchasing and supply': Digital purchase of medicines and medical devices.

The different types of applications classified in the Bertelsmann study each contribute to the digital evolution of the health sector. This evolution describes a networking of individual aspects of the health market into a complex structure of digital health solutions. It promises significantly improved efficiency, with at the same time greatly improved communication between the patient and the actors in the healthcare system and has the potential to bring about savings of almost 10 billion euros. ${ }^{5}$ To date, however, digital offerings in the medical sector are still isolated solutions that, although they bring many advantages in their own right, do not yet really exploit the benefits of a digital turnaround. ${ }^{6}$ It is therefore necessary to further expand these islands and to interconnect them in the course of digital evolution.

\section{The role of pharmacies in digitalized communication with patients}

Pharmacies play a decisive role in this network. They not only ensure the supply of medicines to the population, but are also an important link between doctor and patient. Earlier than many other areas of the health care system, pharmacies have digitalized a large part of their processes. Both ordering and stock management run digitally by default, as do data queries, invoicing or the application of discount agreements. ${ }^{7}$ Increasingly, the digitalization of contact with the customer is now also becoming the focus of technical progress.

In Google's current ranking of medical apps, an app with ordering functions for an online pharmacy is already in 4th place, followed by another in 6th place. They are each credited with over 500,000 downloads. ${ }^{8}$ These figures show all too obviously that even on-site pharmacies have to compete for customers in the digital app market in order to keep up with the growing online competition.

For a partial digitalization of the interaction with the customer, a whole range of apps already offers numerous interesting possibilities for the care and retention of customers by the local pharmacy on site.

The main functions here are:

- Pre-ordering of medicines and pharmacy products

- Easy contact for personal advice

\footnotetext{
${ }^{3}$ Source: AppBrain.com, State 9.2.21.

${ }^{4}$ Cf. Knoppler et al., 2016, p. 13-15.

${ }^{5}$ Cf. Genter, 2016, p. 16.

${ }^{6} \mathrm{Cf}$. Kaindl, 2020.

${ }^{7}$ Cf. Benkert, 2020.

${ }^{8}$ Source: AppBrain, State: 11.2.21.
} 
- Overview of local branches and emergency services

The offer of a personal consultation already differentiates these apps from the pure sales platforms of online pharmacies. This shows that the service advantage of the local pharmacy must also be fully exploited in the digital framework of an app. Thus, these apps serve customer service and marketing in equal measure. Nevertheless, any development of digitalization should be consistently oriented towards patient welfare and not be a pure marketing tool. Their use only makes sense if the quality of care processes is improved and should never be an end in itself. ${ }^{9}$

The providers of the different pharmacy apps range from pharmacy cooperatives and wholesalers to marketing agencies and publishers. They all have different focuses, but basically function similarly. They offer two areas: 1) The customer area which is used with the app on the smartphone; 2) the pharmacy area which allows the employee to interact via a website. ${ }^{10}$

The most popular of these pharmacy apps is currently the app "Deine Apotheke" (engl. Your Pharmacy). It is currently in 14th place in the Google ranking of medicine apps and has over 100,000 downloads. ${ }^{11}$ The multi-channel concept "Deine Apotheke" comes from the Mannheimbased health service provider Phönix. The Phönix Group is at the European forefront as a pharmaceutical wholesaler and pharmacy operator and wants to use the concept to support local pharmacies in Germany, which are responsible for about one third of the group's turnover. ${ }^{12}$ The concept consists of the app and a customer magazine of the same name, which is published in cooperation with Funke Mediengruppe. ${ }^{13}$ Unique among pharmacy apps, "Deine Apotheke" also works with the bonus program Payback and thus provides an additional incentive for customers. The success of this large-scale cooperative proj- ect could point to a development that could also be observed in the digitization of other industries: over time, digital platforms are formed that network several areas and functions with each other. In the end, only a few large providers will be able to prevail due to the development of market concentration. ${ }^{14}$

\section{Perspectives and opportunities}

Already in 2014, a perspective paper was published at the German Pharmacists' Conference, which deals with the possible development of pharmaceutical care in the near future. It deals with the adaptation of pharmacies to scientific and technical progress and an expansion of the range of services..$^{15}$ Norbert Peter, Member of the Board of the Marketing Association of German Pharmacists (Marketingverein Deutsche Apotheker e.V.), concretized the future prospects for pharmacies in 2019, particularly from the aspect of digitalization. ${ }^{16} \mathrm{He}$ points out that especially in times of digitalization, the empathetic and personal bond with the local pharmacist in charge will still be essential. The pharmacist stands as a mediator between the digital and the analogue world of the patient. Nevertheless, the digital services of pharmacies will increase significantly in the next 10 years. According to Peters, these include:

- digitally networked medication plans and increased medication management

- digital therapy monitoring

- regular drug monitoring

- issuing of repeat prescriptions by the pharmacist

These points absolutely presuppose a digitalized health record and perfect networking of the necessary cooperation network of patient, doctor and pharmacist. They are the basic prerequisite for the digital networking of the healthcare system. Patients, doctors and pharmacists benefit

\footnotetext{
${ }^{9} \mathrm{Cf}$. Benkert, 2020.

${ }^{10} \mathrm{Cf}$. Wessinger, 2018.

${ }^{11}$ Source: AppBrain, State: 11.2.21.

${ }^{12}$ Cf. Edalat, 2020.

${ }^{13}$ Source: Funkemedien, Press release from 21.02.2020.

${ }^{14}$ Cf. Kaindl, 2020.

${ }^{15} \mathrm{Cf}$. ABDA, 2014.

${ }^{16} \mathrm{Cf}$. Peter, 2019.
} 
equally from this, as processes become more efficient and can be implemented much more quickly. The optimized processes become significantly leaner, more flexible and more individualized, which increases the overall quality of treatment. ${ }^{17}$ This is an important effect, especially in terms of adherence to therapy, medication safety and dosage safety, which will reduce follow-up treatments due to incorrect medication.

In principle, some of the points mentioned can already be technically implemented today through the isolated solutions mentioned in the form of different health apps. However, the applications are not networked and their use is largely based on the individual responsibility of the respective users. The technical possibilities are therefore given and must now be controlled and securely bundled in an adequate place.

For the best possible patient care, a comprehensive pharmacy app of the future should therefore have the following functions:

- Ordering medicines

- Overview of branches and emergency services

- personal advice

- personal medication plan

- personal health data (at least basic data)

- overview of treatments, therapies and attending physicians

In addition, service aspects, such as a magazine, discount promotions or similar, could be introduced to further strengthen the local pharmacy. All this can be possible via an app.

Even though most pharmacy customers tend to be older people, their use of smartphones should not be underestimated. A survey from 2020 shows that just under half $(48 \%)$ of respondents over the age of 65 would use a health app if asked to do so by a doctor, for example..$^{18}$ In younger years, the acceptance of apps is also much greater in the health sector. Therefore, apps will also be an important tool for on-site pharmacies to communicate with their customers in the future.

\section{References}

1. ABDA-FEDERAL ASSOCIATION (2014). Pharmacy 2030 - Perspectives on Pharmaceutical Supply in Germany.
2. BENKERT T (2020) Basics for digitized pharmacies. In: Rückert \& Pförringer (ed.): With excellent health? Germany in e-health in check-up - future platform Bavaria: digital health system.

3. EDALAT A (2020) Phoenix: 50.000 Orders per month via "Your Pharmacy" app. DAZonline, Stuttgart May 10th, 2020.

4. GENTER A (2014) E-Health perspective consumer solutions as the key to success?, Deloitte study series "Intelligent Networks".

5. KAINDL A (2020). Digitization is the key to better health care. In: Rückert \& Pförringer (Ed.): In the best of health? Germany in ehealth in check-up - future platform Bavaria: digital health system 2020.

6. KNOPPLER K., NEISECKE T, NOLKE L (2016). Digital-Health-Anwendungen für Bürger - Kontext, Typologie und Relevanz aus Public-Health-Perspektive. Bertelsmann Foundation.

7. KNOPPLER K, STENDERA P (2019) Transfer of digital health into everyday care. In: Haring, R. (Ed.), (2019), Health digital Perspectives on digitization in health care, Springer.

8. PETER N (2019) Is that the breakthrough? The BMG's digital plans from a pharmacy's point of view - opportunities and potential for better care. In: The breakthrough? - The digital plans of the BMG from the perspective of the actors. Discussion on health policy forum, April 2019.

9. WESSINGER S (2018) Which mobile phone apps are there for pharmacists and their customers? DAZ.online, Stuttgart - March 13, 2018.

${ }^{17}$ Cf. Ganter, 2014, p. 18.

${ }^{18}$ Source: Statista, Juli 2020Can you imagine using apps on prescription? 